\title{
Analysis of Factors Influencing Consumers in Using the E-Wallet Application
}

\author{
Syafira Salzabella $^{1}$, Ujang Sumarwan ${ }^{1}$, Lilik Noor Yuliati ${ }^{1}$ \\ ${ }^{1}$ IPB University, School of Business, Jl. Raya Pajajaran Bogor, Indonesia \\ Corresponding Author: Syafira Salzabella
}

\begin{abstract}
The development of electronic money in Indonesia is quite rapid, this is proven to increase the volume of electronic money transactions in 2020 estimated to reach 3.7 billion with the number of electronic money in circulation of 51 electronic money. This research uses TAM which is a model that identifies the acceptance and use of technology for consumers, in this case the e-wallet application. The variables in this study include perceived ease of use, perceived usefulness, advertisements, cashback promos, product innovation and intention to use. This research aims to: 1) analyze demographics, perceived ease of use, perceived usefulness, advertisements, cashback promos, product innovation and the intention to use the e-wallet application services;2) analyze the factors affecting consumers in using the e-wallet application; 3) formulate managerial implications that can be implemented by service providers to increase the use of e-wallet applications. The study was conducted from August 2020 to March 2021. The number of samples used in this study was 407 respondents. Data analysis used descriptive statistics and SEM (Structural Equation Model) with SmartPLS software. The results showed that creating user friendly features to attract new users and retain old users; maintaining the quality of transaction services in terms of speed, convenience and practicality; improving service access when topping up and transferring balances to other users; service providers need to educate and socialize about e-wallets by utilizing cashback promos; improve security systems to safeguard users' personal data; there is a need for a legal protection for application
\end{abstract}

users; and increasing the number of merchants on e-wallet applications.

Keywords: intention to use, behavioral intention, e-wallet, TAM, payment method.

\section{INTRODUCTION}

The Internet is one of the factors that causes the development of information technology. Internet users in Indonesia are projected to grow by 149.9 million users in 2023 or grow by $13.3 \%$ from 2017 (Statistics 2019). One of the activities performed by internet users is shopping in e-commerce by making payments online. As many as $96 \%$ of internet users use to shop in e-commerce and make online payments with mobile phones as much as $79 \%$ (We Are Social 2019). It shows that the internet and information technology cause changes in activities and needs of life so that the current direction of business is largely adjusted to these developments. Non-cash payments are now widely used by the public to make transactions in various types of debit cards and credit cards, but electronic money. The use of electronic money has increasingly gained a boost from Bank Indonesia regarding interbank cooperation and transportation operators in 2014.

Electronic money itself is divided into two kinds, namely chip-based electronic money and server-based electronic money. Server-based electronic money products are commonly known as ewallets. The working system of e-wallet is in the form of withholding balance in the user's account (Trihasta \&Fajaryanti 2008). 
The use of e-wallet is done online through a computer or smartphone, users only need to share a phone number or QR scan to receive or send money. E-wallet service is a convenient, effective, and efficient solution for people to run a business and pay bills without having to leave the house or take money at an ATM (Pratami 2018). There are 10 widely used e-wallets in Indonesia judging by the total number of app downloads and monthly active users namely Go-Pay, Ovo, Dana, LinkAja, Jenius, Go Mobile, iSaku, Sakuku, Doku and PayTren (iPrice 2019).

The technology acceptance model has been developed over the past few years using the Technology Acceptance Model (TAM) is one of the most common theories used to explain individual acceptance of the use of information technology systems. This model is fundamental to constructs, namely perceived usefulness, perceived ease of use, attitude toward using, behavioral intention to use and actual use (reality of use) (Venkatesh \&Bala 2008).

\section{METHODS}

The approach used in this study is a quantitative approach with survey methods. The type of survey used in this study is a cross sectional survey, a survey that is only conducted at a certain time (Nazir, 1998). The research was conducted during August 2020 until March 2021. Spread online questionnaire with Google form through WhatsApp Group and Instagram researchers.

This research is a descriptive research conducted by survey method to users of e-wallet applications on social media. The survey approach uses a list of questions (questionnaires) to respondents. Descriptive approach to explain the situation and characteristics of respondents of e-wallet application users, while to examine the relationship of influence of each variable using SEM approach.

The method used in this study was Voluntary Sampling. According to Al-Assaf (2009) voluntary sampling is a sampling method consisting of people who choose themselves into the survey. The population is divided into two groups, namely the first, users of e-wallet applications originating from WhatsApp Group and secondly, users of e-wallet applications originating from Instagram (username: Syafira Salzabella). The population is assumed to be an active user of the e-wallet application. The dissemination of questionnaires is done by disseminating personal Google form links with the following criteria:

1. Have at least one e-wallet app

2. Using the e-wallet app in the past week

The first population group came from WhatsApp group of 119 people where 82 of them were also friends on Instagram, while 37 others were only friends in WhatsApp group. In disseminating questionnaires in WhatsApp group, researchers took samples from people who were only in WhatsApp group, which is as many as 37 people while 82 others will be included in the population that comes from Instagram. Furthermore, the second population group came from Instagram as many as 305 people. This number is included in the 82 people who are also from WhatsApp group. So the total population in this study was 342 people.

According to Hair et al. (2006), the number of samples needed for each estimate of exogenous and endogenous variable parameters is five to ten observations. The number of indicator variables that make up the model in this study is as many as 30 indicator variables or attributes so that if for each variable needed five to ten observations, then the limit of the number of samples is between $30 \times 5=150$ people to $30 \times 10=300$ people.

During the data collection time collected the number of samples as many as 407 respondents. Based on the results of the questionnaire, a total of 224 respondents came from whatsapp group and instagram. While 183 respondents came from outside whatsapp group and instagram. The presence of respondents from outside whatsapp group and instagram is caused by 
researchers also spread questionnaires via broadcast whastapp group and instagram story.

The data used in this study are primary data and secondary data. Primary data is obtained from the results of questionnaires containing a list of questions that are systematically compiled and will be filled by respondents in accordance with the actual situation. The questionnaire was filled out by the respondents themselves. Data collection is done by disseminating online questionnaires through google form widely to target respondents spread through social media. Secondary data is data that is not obtained directly by researchers or there are other parties who take the data (Sumarwan, 2017). For secondary data this research is obtained from journals, theses, scientific works, articles and various related literature.

The types of questions in this questionnaire are multiple choice and rating scale. The scale used in the questionnaire scale of this study is the ordinal scale. An ordinal scale is a scale that describes the ranking (Sumarwan, 2017). The measurement of the study variables was conducted on a Likert scale. The likert scale range uses a weight range from 1 to 5 . The weight given is weight $1=$ strongly disagree, weight $2=$ disagree, weight $3=$ hesitation, weight $4=$ agree and weight $5=$ strongly agree. Answer writing based on Likert scale is used for data processing with Structural Equation Model (SEM).

Perceived usefulness has five indicator variables. In the first indicator, $92.88 \%$ of respondents stated that the ewallet application can be used anywhere (PU1). There are $95.33 \%$ of respondents stated that the security level of frequently used e-wallet applications is good (PU2). Variable transaction speed indicator (PU3) as many as $93.86 \%$ of respondents stated that e-wallet applications that are often used have a good transaction speed rate. Due to the good transaction speed, $91.40 \%$ stated that e-wallet applications make their transaction activities more practical (PU4).
In the last indicator in perceived usefulness, $87.47 \%$ of respondents stated that e-wallet applications provide cheaper transaction fees (PU5).

Perceived ease of use has five indicator variables. In the first indicator, $92.38 \%$ of respondents stated that frequently used e-wallet applications have an easier registration process (PEOU1). 99.02\% of respondents said e-wallet applications provide easy-to-understand transaction procedures (PEOU2). Meanwhile, 99.02\% of respondents stated that the features in the e-wallet application are easy to operate (PEOU3). In addition, $92.88 \%$ of respondents stated that e-wallet applications that are often used are good at creating and updating their services according to the needs of respondents (PEOU4). Lastly, $99.02 \%$ of respondents stated that they can top up their e-wallet application balance anywhere and anytime (PEOU5).

\section{Advertisement}

The ad variable consists of five indicators. In the first indicator, $77.40 \%$ of respondents stated that e-wallet applications that are often used quite often appear on television (IK1). There are $94.35 \%$ of respondents who say they often hear the ewallet application used appear on radio broadcasts (IK2). Meanwhile, $85.26 \%$ of respondents stated that e-wallet applications that are often used appear on social media (IK3). In addition, about $85.26 \%$ of respondents stated that they had seen a frequently used e-wallet application appear on billboards on the street (IK4). Lastly, $51.10 \%$ of respondents said that frequently used e-wallet applications often advertise their service products on the app on smartphones.

Cashback promos have five indicator variables. Approximately $79.85 \%$ of respondents stated that the e-wallet application that is often used provides the most cashback (PDC1). One of the purposes of users transacting using e-wallet application is because of cashback (PDC2) with a percentage of $68.80 \%$ of respondents. 
Meanwhile, $60.69 \%$ of respondents stated that e-wallet applications are often used in cooperation with merchants who provide the most cashback (PDC3). In addition to providing promos for existing users, about $59.46 \%$ of respondents stated that the ewallet application provides promos for new users (PDC4). Lastly, $78.63 \%$ of respondents stated that the amount of cashback given by the e-wallet application was in line with expectations.

Product innovation has five indicators. In the first indicator, $84.77 \%$ of respondents stated that the frequently used e-wallet application has features for managing finances (IP1). There are $98.04 \%$ of respondents stated that the e-wallet application that is often used has cooperated with many e-commerce (IP2). About $62.90 \%$ stated that frequently used e-wallet apps have a balance transfer feature to fellow app users (IP3). In addition, about $87.22 \%$ of respondents stated that the frequently used e-wallet application has a paylater (IP4) feature. Lastly, 93.36\% of respondents stated that frequently used ewallet applications can top up in stores (IP5).

Consumer interest in using e-wallet applications is measured through five indicator variables, namely transaction options and future usage. Variable indicators related to transaction options are e-wallet applications that respondents often use to have a feature that determines the type of payment (IU1) of $79.36 \%$. The other indicator variables related to the choice of transaction is about $70.27 \%$ e-wallet applications that are often used in cooperation with many merchants (IU2). The next three indicator variables relate to consumers' plans to use e-wallet applications in the future. There are $92.88 \%$ of respondents feel that e-wallet application is good enough to offer promos when transacting (IU3). A total of $98.46 \%$ will use the e-wallet application continuously in the future (IU4). Lastly, all respondents stated that overall the e-wallet application that is often used is very good, so it is appropriate to be introduced to other users to use the e-wallet application (IU5).

\section{RESULTS \\ Respondent Demographic Characteristics}

The sample of this study is e-wallet users who come from whatsapp group and Instagram. Demographic characteristics in this study are age, gender, marital status, education level, occupation, expenditure and domicile.

Gender is an important component of marketing, but not all products and services can be distinguished by this segment. Respondents to the study were dominated by women with a total percentage of $57 \%$. According to Sumarwan (2011) understanding the age of consumers is important, because consumers of different ages will consume different products and services. Based on the results, e-wallet app users are dominated by millennials with an estimated age of 25 to 40 years, which is $90.66 \%$ of the total sample. That age range shows that the productive age range is more using e-wallet apps. In this generation respondents have a high level of productivity so using an e-wallet application is expected to facilitate their activities after being able to increase productivity. In addition, $75.68 \%$ of respondents obtained in this study had married marital status.

The level of education will affect the process of consumers making choices over the goods and services consumed or used. A person's level of education will also influence the values they follow, their way of thinking, their perspective and even perception of a problem. The level of education in this study is divided into five categories, namely High School (SMA), Diploma (D3), Bachelor (S1), Postgraduate (S2), and Doctoral (S3). The education level of respondents from this study was dominated by scholars who reached $72.24 \%$, while the minimum level of education was doctorate by $0.74 \%$.

The user's profession often indicates the social status of the user. The profession that cendurung has influences the behavior 
of users in making product purchases. The professions of respondents in this study were divided into six categories, namely students, private employees, civil servants, entrepreneurs, housewives and professionals. Based on the results of the study, the profession of respondents in this study is a private employee. A total of $39.56 \%$ of respondents in this study were private employees. The second position is occupied by civil servants at $16.71 \%$. The profession with the lowest percentage is occupied by professionals around $3.93 \%$.

Information on monthly expenses is required to know the respondent's economic background. Monthly spending data can describe which group of respondents with monthly expenses uses electronic money applications the most. In this study, respondents' monthly expenses were divided into two categories, namely non-eating expenses and meal expenses. Non-meal expenses include education costs, health costs, household facilities, goods and services and entertainment. While the expenditure of food such as eating and drinking so as well as daily basic needs. Non-food and food expenditures are divided into seven categories, namely $<\mathrm{Rp}$ 1,000,000; Rp 1.000.001 - Rp 2.000.000; Rp 2.000.001 - Rp 3.000.000; Rp 3.000.001 - Rp 4.000.000; Rp 4,000,001 - Rp $5,000,000$ and $>$ Rp 5,000,000 Food expenditure per month respondents in the study were dominated by a group of $\mathrm{Rp}$ 3,000,0001 - Rp 4,000,000 36\%. While the last position is the spending group $<\mathrm{Rp}$ 1,000,000 and Rp 1,500,000 - Rp 2,000,000. Meanwhile, non-food expenditure per month was dominated by a group of $\mathrm{Rp}$ $3,000,000$ - Rp 3,500,000 per month of $25 \%$. While the last position is the spending group of Rp 1,500,000 - Rp 2,000,000 by $0.2 \%$.

\section{E-Wallet User Behavior}

The behavior of e-wallet users by respondents is obtained through several related questions addressed through questionnaires. The questions asked relate to the type and length of ownership, source of information introduction, reasons and situations of use, nominal per transaction and frequency of use. Table 9 shows the distribution of respondents based on user behavior with a sample of 407 users. Respondents responded based on the most frequently used e-wallet usage when having more than one e-wallet application.

The development of electronic money applications has an impact on the emergence of various electronic money products, namely e-wallets. Based on the results of the study, $71.25 \%$ of respondents had 3 to 4 e-wallet applications on their smartphones, accounting for $39.80 \%$ of merchant cooperation. In addition, some respondents have been using e-wallet applications for 2 to 3 years. This indicates that there has been an increase in consumer demand for e-wallet applications that are considered more practical. The first e-wallet application owned by respondents is GoPay. Go-Pay became the most used e-wallet application for the first time, followed by OVO, Dana and LinkAja. Go-Pay and OVO have been adopted ahead of Dana and LinkAja.

Based on the results of the study, $79.12 \%$ of respondents used e-wallet application twice in one week. The nominal transaction last time spent by respondents was dominated by the spending group of Rp 200,000 - Rp 300,000 of $35.13 \%$. While the last position is the spending group of $\mathrm{Rp}$ 300,000 - Rp 400,000 of $3.44 \%$. Cashback is the main reason that influences users to shop on online platforms. Based on the distribution of respondents, cashback food or beverage messages between online became the cashback most taken by respondents. 39\% of respondents used the online food or beverage delivery cashback offered by their most used e-wallet app. While online transportation cashback has a percentage of $25.80 \%$, retail cashback of $20.39 \%$ and cashback of food or beverages in outlets as much as $14.50 \%$.

Based on the spread of respondents, it appears that most of the types of 
transactions made by respondents with ewallet applications that they use the most are the purchase of food or beverage delivery online by $46.19 \%$, followed by online transportation payments (29.97\%), bill payments (15.48\%), online shopping payments $(5.65 \%)$ and food or beverage purchases at outlets (2.71\%). Meanwhile, the last type of transaction used by respondents was dominated by online transportation payments of $36.85 \%$. While the last position for the type of transaction last used by respondents was the purchase of food / beverage in stores / restaurants / malls by $3.69 \%$.

The development of electronic money has an impact on various sectors, one of which is consumer behavior in online shopping. Most e-wallet users make online transactions because it is considered more practical, time efficiently secure. In this study, there were three reasons respondents chose to use the most frequent application. First, as many as $48 \%$ of respondents make convenience as the reason to use the ewallet application most often because they do not need to bring cash and do not have to worry about change and money fitting. Second, the ease of transactions makes $28.99 \%$ percent of respondents choose to use the most frequent applications because the transaction processes and features offered are more practical. Third, $25.80 \%$ of respondents use the most frequent application because of the cashback offered by the application.

E-wallets are becoming one of the payment innovations that are increasingly being used by the public. Its functionality that offers a more practical, efficient and secure payment system makes e-wallet a new business model. The development of ewallets on the one hand is proven to bring benefits to consumers, businesses and the national economy. In this study, the distribution of respondents about the source of information on e-wallet applications first had quite diverse data. But the top three sources of information were told by friends (44.96\%), family $(25.80 \%)$ and social media
(9.58\%). This means that information from friends, family and social media greatly influences consumers' interest in using the most frequent e-wallet apps. These three things can be used as the focus of the growth of e-wallet applications in order to reach more new consumers.

\section{Factors Influencing Consumer Interest in Using E-Wallet App}

The analysis tool used in this study is structural equation modeling (SEM) using partial least square (PLS) approach. The SEM model in this study used 407 respondents in Jabodetabek area who were at least 15 years old and became active users on the e-wallet application. The variables studied in this study are perceived usefulness, perceived ease of use, advertising, cashback promos, product innovations, and intention to use with each indicator it has. Data of respondents who have passed the validity and reliability test of instruments using SPSS is continued to the analysis stage using SmartPLS. There are three stages in SEM-PLS analysis, the first stage is outer model analysis, the second stage is inner model analysis, and the third stage of hypothesis testing.

Analysis of the measurement model was conducted to determine the validation and reliability of the model measurement in the study. Outer model analysis relates to the relationship between latent variables and their indicators so that through the evaluation of outer models can be known the extent to which an indicator can explain latent constructs in the research model. The outer model evaluation consists of convergent validity, discriminant validity, composite realibility, average variance extracted (AVE), and cronbach's alpha.

Convergent validity can be seen from the value of latent variable loading factor against the indicator which shows the size of the validity of each indicator as a latent variable manifest. The indicator can be said to be valid if the loading factor value is above 0.7 and can still be considered valid up to 0.5 (Latan and Ghozali 2012). 
Discriminant validity is the value of cross loading tested to find out if the construct has sufficient discriminant. The cross loading value of an indicator on the intended latent variable should be higher than the cross loading value with other latent variables. Composite realibility is measuring the true reliability value of a variable. Variables with a composite realibility value of $>0.7$ are considered to have high reliability (Ghozali and Latan 2015). The recommended average variance extracted (AVE) is > 0.5 (Chin 1998). The recommended AVE value is more than 0.5 which means that $50 \%$ more variance than the indicator can be explained (Ghozali and Latan 2015). Cronbach's alpha reliability test can be strengthened by the presence of cronbach's alpha test. This test is conducted to measure the lower limit of the reliability value of a variable. The received value is if the value is above 0.7 (Ghozali and Latan 2015).
The invalid indicators are cheaper transaction fees (PU5), in cooperation with many merchants who provide the most cashback (PDC3), provide promos for new users (PDC4), cashabck nominal in accordance with expectations (PDC5), there are features to manage finance (IP1) and cooperate with many e-commerce (IP2). So the results concluded that the convergent validity test has not been met. This means that the existence between correlations between different instruments is not yet validenough.

The result of the removal of invalid items is shown in Figure 1 which is a cheaper transaction fee (PU5), using an ewallet application saa no cashback (PDC2), in cooperation with the merchant who gives the most cashback (PDC3), providing promos for new users (PDC4), nominal cashback in accordance with expectations (PDC5), there is a feature to manage finance (IP1), cooperate with many e-commerce (IP2), and can top up outlets (IP5).

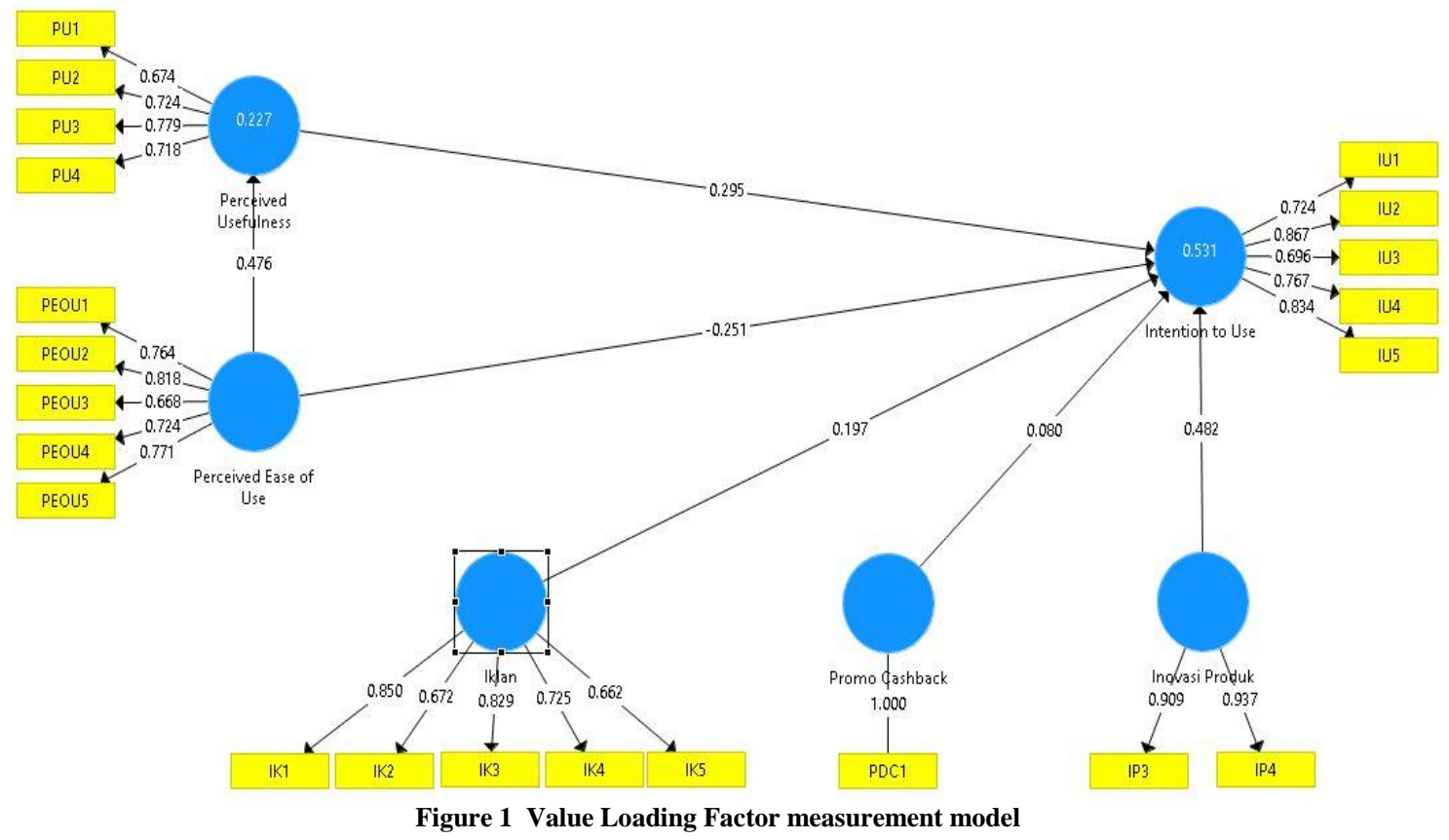

The definition of the loading factor value basically shows the magnitude of the correlation between the indicator and its latent construct. The higher the value of the loading factor states that the indicator contributes highly to its latent construct.
Conversely, if the loading factor value is low then the contribution of the indicator in explaining latent constructs is also fairly low. Based on the acquisition of loading factor variables perceived usefulness described by four indicators can be used 
anywhere (PUI), making transactions safer (PU2), making transactions faster (PU3), making transactions more practical (PU4) and cheaper transaction fees (PU). Based on the results of the loading factor value can be seen that the highest indicator value is found in PU3 makes transactions faster with the acquisition of 0.779 . The results stated that e-wallet applications that respondents often use make transactions faster contributing $77.9 \%$ to the latent value of variables perceived usefulness.

Could be seen that the value of loading factor on the indicator perceived ease of use is entirely above 0.5 . This means that all perceived ease of use indicators are valid. The results show that the variable perceived ease of use is explained by five indicators, namely the easier registration process (PEOU1), easy-to-understand transaction procedures (PEOU2), easy-tooperate features (PEOU3), up to date (PEOU4) features and easy-to-do top ups anywhere (PEOU5). Could be known that the highest loading factor value is in PEOU2 transaction feature is easy to understand with the acquisition of 0.818 . The results stated that e-wallet applications that are often used by respondents have an easy-to-understand transaction feature has a contribution of $81.8 \%$ in explaining variables perceived ease of use.

Could be seen that the loading factor value on the ad indicator is entirely above 0.5 . This means that all ad indicators are eligible. The value of loading factor on advertising variables can be seen in Table 19. The results show that the advertising variables are explained by five indicators, namely advertising the application through television (IK1), advertising the application through radio (IK2), advertising the application through youtube (IK3), advertising the application on the billboard (IK4) and advertising the application through a smartphone application (IK5). Could be known that the highest loading factor value is in IK1 advertising its application through television with the acquisition of 0.850 . The results stated that e-wallet applications that respondents often use to advertise their applications through television have an $85 \%$ contribution in describing advertising variables.

Could be seen that the value of loading factor on the cashback promo indicator is not entirely above 0.5 . There are several items that need to be removed in this case namely PDC3 (-0.297), PDC4 (0.166) and PDC5 (-0.038). The result of deleting the item will be shown in Table 20. Variabel cashback promo can only be explained by one variable namely PDC1 gives the most cashback with the acquisition of 1.00. The results stated that e-wallet applications that are often used by respondents to give the most cashback have a $100 \%$ contribution in explaining the variables of cashback promos.

Could be seen that the value of loading factor on product innovation indicator is not entirely above 0.5 . There are several items that need to be removed in this case, namely there is a feature to manage finance (IP1), cooperate with many ecommerce (IP2), and can top-up in stores (IP5). Variabel product innovation can only be explained by two indicators namely IP3 can transfer balances to other users and IP4 there is a paylater service. As for Table 21, it can be known that the highest loading factor value is IP 3 can transfer balances to other users with the acquisition of 0.909 . The results stated that e-wallet applications that are often used by respondents have a balance transfer feature to other users has a contribution of $90.9 \%$ in explaining product innovation variables.

Could be seen that the value of loading factor on the intention to use indicator is entirely above 0.5 . This means that all intention to use indicators are valid. The variable intention to use by five indicators is that there is a feature to determine the type of payment (IU1), cooperate with many merchants (IU2), offer the best promotion when transacting (IU3), increase the frequency of user (IU4) and invite others to use (IU5). It can be known that the highest loading factor value is in 
IU2 in collaboration with many merchants with an acquisition of 0.867 . The results showed that respondents will use the ewallet application if the e-wallet application in cooperation with many merchants has a contribution of $86.7 \%$ in explaining the variable intention to use.

The overall value of the indicators on six variables has had a loading factor value above 0.5 thus indicating that the indicators are valid as manifest variables (Hair et al 2006). In addition to using convergent validity, validity tests can also be performed by looking at the Average Variance Extracted (AVE) value. The AVE value for the convergent validity test can be seen in table 1

Table 1 AVE Value

\begin{tabular}{|c|c|}
\hline variable & Ave. \\
\hline Perceived Usefulness & 0.525 \\
\hline Perceived Ease of Use & 0.564 \\
\hline advertisement & 0.565 \\
\hline Cashback Promo & 1.000 \\
\hline Product Innovation & 0.852 \\
\hline Intention to Use & 0.609 \\
\hline
\end{tabular}

Based on Table 1 it can be seen that the AVE value shows more than 0.5 so it can be said that each indicator used in this study has had a fairly good validity value. The next test conducted is reliability test. The parameters used to know reliability are cronbach's alpha and composite reliability. The value gain for the reliablitas test can be seen in Table 2

\begin{tabular}{|} 
Table 2 Reliability test values \\
\begin{tabular}{|c|c|c|}
\hline Latent Variables & $\begin{array}{c}\text { Composite } \\
\text { Reliability }\end{array}$ & $\begin{array}{c}\text { Cronbach's } \\
\text { Alpha }\end{array}$ \\
\hline Perceived Usefulness & 0.815 & 0.698 \\
\hline $\begin{array}{l}\text { Perceived Ease of } \\
\text { Use }\end{array}$ & 0.865 & 0.812 \\
\hline advertisement & 0.865 & 0.830 \\
\hline Cashback Promo & 1.000 & 1.000 \\
\hline Product Innovation & 0.920 & 0.828 \\
\hline Intention to Use & 0.885 & 0.841 \\
\hline
\end{tabular}
\end{tabular}

In Table 2 it can be seen that based on the value of cronbach's alpha the latent variable used has been reliable because it has a value of more than 0.7. Similarly, the value of composite reliability has an overall value above 0.6 . These results show that the reliability of the latent variables used in this study has been met. The last test performed was a discriminant validity test. Testing was conducted on the principle that the manifest variables of different constructs should not be highly correlated (Ghozali 2014). Another way to test discriminate validity is to compare the root value of each construct's average variance extracted (AVE) with the correlation between constructs and other constructs. In accordance with Table 2 it is true that ave root values are higher to correlation between constructs and other constructs, so it can be said that the model has qualified discriminant validity.

Structural model evaluation is done by analyzing the value of coefficient of determination or $\mathrm{R} 2$, coefficient path value and t-statistics value. The $\mathrm{R} 2$ value is seen from the construct of an endogenous variable or an affected variable. According to Chin (1998), R2 values are categorized into three categories, namely R2 values 0.67 (strong), 0.33 (moderate) and 0.19 (weak). The value of $\mathrm{R} 2$ can be seen in Table 3 .

Table 3. value of R2
\begin{tabular}{|c|c|}
\hline Latent Variable & R-Square (R2) \\
\hline Perceived Usefulness & 0.227 \\
\hline Intention to Use & 0.531 \\
\hline
\end{tabular}

The endogenous variables used in this study had the majority of R2 values that fall into the moderate category. The first R2 value is perceived usefulness, perceived ease of use, advertising, cashback promos, and product innovations are able to explain the diversity of intention to use by 53.1 percent and the rest is explained by other independent variables that are not in this research model. Then the second $\mathrm{R} 2$ value is perceived ease of use is able to explain the diversity of perceived usefulness by 22.7 percent and the rest is explained by other independent variables that are not in this research model.

\section{Hypothesis Testing}

Variable perceived ease of use affects perceived usefulness. The results showed that the effect of perceived ease of use on perceived usefulness had the greatest 
value of 15,334 . Meanwhile, $t$ calculate 4974 or $>1.96$ and $p$ values 0.000 or $<0.05$, meaning the first hypothesis is accepted. The positive value in the results of this study shows that the increasing value of perceived ease of use, the perceived usefulness of the most frequent use of ewallet applications will also increase. This is because, users believe the perception that the e-wallet application that is often used has features that are easy to use, making the user believe that the features of the e-wallet application have benefits for the user. The results of this study are in line with Adhiputra (2015) and Im and Hancer (2014) which presented that perceived ease of use has a significant effect on perceived usefulness

The benefits of using it directly affect the perception of the usefulness of ewallet app users. Before users feel the usefulness of the e-wallet application, users should feel confident that using the e-wallet application for payment transactions is easy. Procedural and procedures for using ewallet applications do not complicate, the features on the e-wallet application are more up to date and users can top up via bank or mobile banking so as to give rise to the perception of ease of use. The procedure that must be passed by the user to be able to use the e-wallet application is to download the e-wallet application on the user's smartphone and then register by entering the email address and mobile number. With easy procedures and also uncomplicated transaction tools in addition to making transactions with e-wallet applications make users spend cheaper transaction fees so that users will assume with the e-wallet application makes transactions can be done anywhere, safer, faster lebih practical and cheaper.

Perceived usefulness variables affect intention to use. The results showed that the effect of perceived usefulness on intention to use had a value of 4,971. Meanwhile, $t$ calculate 4974 or $>1.96$ and $p$ values 0.000 or $<0.05$, meaning the second hypothesis is accepted. The positive value in the results of this study shows that the increasing value of perceivedd usefulness, the intention to use the most frequent e-wallet applications will also increase. This is in accordance with the results of research from Nursiah (2017) said that perceived usefulness has a significant and positive effect on intention to use.

Perception of usability in using ewallet applications influences the user's interest to use the application. Users with high mobility need flexible transaction tools that can serve to improve user productivity and performance. Users who have used the e-swallowing application feel helped because there is no need to transact payments such as transferring funds, paying electricity, paying bills and others. Users only simply using the e-wallet application can make payment transactions in their place simply by connecting their smartphone and internet network. This makes the payment transaction activities faster and more practical. Certainly, provide benefits for users in terms of time and effort. This allows users of e-wallet apps to increase their productivity

Based on the results of the above research, it can be concluded that the perception of benefits in the e-wallet application affects the interest of using ewallets that can be used anywhere, making transactions safer, making transactions faster, making transactions more practical and transaction fees cheaper. These values serve as adhesives and can be used as a reference for service providers in attracting users to use e-wallet applications.

The results of the respondent's assessment showed the perception of benefits was able to attract respondents in using e-wallets. This is because respondents feel that by using e-wallet all payment transaction needs can be met right then and there can be done in one e-wallet application installed on the respondent's smartphone. In addition, e-wallets are also easy to carry anywhere with a large balance limit and balance replenishment can be done anywhere. 
The variable perceived ease of use has a significant effect on intention to use with a calculated $t$ value of 4,955 or $>1.96$ and a $p$ value of 0.000 or $<0.05$. With these results, it can be said that the third hypothesis is accepted. The positive value in the results of this study shows that the increasing value of perceived usefulness, the intention to use the most frequent e-wallet applications will also increase. This result is in line with Wibowo et al research (2015) found that the perception of ease of use positively affects the interest in the use of electronic money.

The perception of ease in using ewallet applications has an influence on the user's interest in using e-wallets. Similarly, Ramadhan \&Prasetyo research (2016) also explained that there is a positive influence between the perception of ease of use to the interest in using e-wallet applications. So it can be concluded that from the study stated that if the individual feels confident that the information system is easy to use, then he will use the information system.

This means that the $\neg$-wallet application is not difficult to use by the public because the way of use is considered easy, so the public becomes $\neg$-wallet as an alternative means of transactions to make payments. In addition, there are many outlets in jabodetabek area that become one of the places to top up e-wallet balances to make top up easy.

Based on the results of the above research, it can be concluded that the perception of ease in using e-wallet applications affects the user's interest to use the e-wallet application. Users tend to think of e-wallets as an inseparable part of payment transactions. Payment system on ewallet itself can be done by users in various ways. Where after top up, users can use it to buy and transact online goods or services. This payment process is different from card payments, as long as the user's payment process is authenticated, the user has access to the features and functionality of his ewallet application account (Centerklik, 2019). The majority of respondents stated that they use e-wallets for online transportation payment transactions. So it can be concluded that the ease of e-wallet application is understood and used by users can attract users in using e-wallet as a means of online payment transactions.

Ad variables have a significant effect on intention to use variables. This can be seen from the calculated $t$ value of 4,947 or $>1.96$ and $p$ values of 0.000 or $<0.05$. Thus, the fourth hypothesis is acceptable. The positive value in the results of this study shows that the better the e-wallet application ads appear, the intention to use users against the most frequent e-wallet applications will increase. The analysis is in accordance with the results of Khanfar's research (2016) which states that advertising positively affects the interest in using ewallets because advertising as a promotional tool serves to communicate the value of users persuasively so that there is an interest in using the service.

Ads displayed by e-wallet service providers influence users' interest in using ewallets. The same result was also stated by Pandjaitan (2013) that the better the advertising will have an impact on increasing public interest in an advertised product. The same was also stated by Manorek (2015) which stated that advertising plays an important role in the introduction of a product, without advertising the public will not be aware of the existence of a product, therefore public interest in a product will also not arise. In this study e-wallet providers advertised their applications through television, radio, YouTube, billboards and applications on smartphones. The majority of respondents stated that it is often used to advertise ewallet applications that are often used through television.

The results of the respondent's assessment showed that the advertisement was able to attract respondents in using ewallets, namely advertising through television, fish through the radio, advertising through YouTube channels, advertisements through billboards and 
advertisements through applications on smartphones. Based on the results of the study, television advertising has the most value, followed by advertising through billboards in the second position. In line with the results of nielsen consumer \&media view report (2017) shows that the penetration of people who see billboards in Indonesia ranked second, reaching $52 \%$ of the total population, while the first position, was established by those who watched TV, where penetration reached $96 \%$ of the total population. This makes some e-wallet service providers make billboards as a medium to campaign their brands and products.

Promo becomes the initial attraction of consumers in using e-wallets. But along with the intenistas of the use of e-wallets, consumer loyalty also arises. Where consumer loyalty is influenced by the convenience and quality of service provided by e-wallet service providers to consumers. Based on the results of research conducted on users of e-wallet applications as a means of payment transactions, it was obtained that cashback promos negatively affect the variable intention to use with a t count value of 1,320 or $<1.96$ and $p$ values of 0.188 or $>0.05$. Thus, the fifth hypothesis was rejected. The negative value in the results of this study shows that cashback promos do not affect respondents to use e-wallets. The results of this study are in line with Agus et al (2019) which states that the promo has no significant effect on the interest in using ewallets. This is because millennial consumers, especially e-wallet users, do not really care about the amount of promos provided by service providers, so the promos provided do not have much effect on the growing interest in using e-wallet applications.

In ipsos research (2020), most respondents said they would still make transactions with e-wallets even without cashback promos. This is because $68 \%$ of users choose to use e-wallets because of convenience, the remaining $23 \%$ because of promotions and $9 \%$ because of security. The type of transaction is $36 \%$ of respondents stated that online transportation service payments will still be used even without cashback promo. Furthermore, online food and beverage purchases (29\%), food and beverage purchases at outlets (14\%) and bill payers $(6 \%)$. While the e-wallet application with the highest percentage that will still be used by respondents even if it does not provide cashback promo for users is GoPay by $54 \%$, followed by OVO (29\%), DANA $(11 \%)$ and LinkAja $(6 \%)$. So it is recommended for e-wallet service providers not to rely on promos anymore but to improve the convenience of users who put forward functionality, innovation and product quality.

Variable product innovation has a significant effect on intention to use with a calculated t value of 8,380 or $>1.96$ and a $p$ value of 0.000 or $<0.05$. With these results, it can be said that the sixth hypothesis is accepted. The positive value in the results of this study shows that the higher product innovation available in e-wallet applications, the intention to use users to use e-wallet applications. The results of the study support research conducted by Agustina (2017), Abrilia \&Sudarwanto (2020) and Fatonah \&Hendratmoko (2020) which found that the service features become one of the attractiveness that can attract users in scolding e-wallets. in addition, this study also supports Agustina's research (2017) on variable service features significantly has an influence on the interest in using the internet

Based on the results of the Ipsos survey (2020), e-wallet users want a variety of innovations that make it easier for them. E-wallet users are dominated by generation $\mathrm{Z}$ and millennials. This group of users wants innovations in services such as e-wallets that collaborate with banking services, connect with savings and payments can be dicicil. For example, DANA e-wallet provides Card Binding feature. With this feature, DANA e-wallet users can store debit cards in the e-wallet application to be 
a source of funds when transacting so that users do not have to top up again.

The results of respondents' assessment showed that service innovations are able to attract consumers to use ewallets, namely there are features to manage finance, cooperate with many e-commerce, can transfer balances to other users, there are paylater services and can top up outlets. In the management of variable indicators of product innovation stated hassil agreed in each indicator, this is because in this study respondents were dominated by the age category of 20 years to 41 years. In accordance with the results of the Ipsos survey (2020), this age category falls into the category of being able to absorb new innovations. They consider that the features of the services available on the e-wallet application are already able to help them in their daily lives.

E-wallet service providers state that initially the utilization of e-wallets does need to be started by providing a variety of cashback promos, but the service provider realizes that users of e-wallet applications feel the convenience and security when using the application. The service provider says e-wallet users will transact even if there is no promo because the user considers the e-wallet application practical and safe. In addition, e-wallet service providers must be creative in providing convenience for users by creating new service innovations

\section{CONCLUSIONS}

All respondents based on demographic aspects have quite diverse data. However, respondents were dominated by the age category of 20 - 30 years and the level of education of undergraduate students. The distribution of respondents based on user behavior indicates that the majority of respondents have been using ewallets for $2-3$ years and families as the first source of information in using ewallets. The majority of respondents have 3 to 4 e-wallet apps in their smartphones. Respondents made merchant cooperation the main reason for choosing an e-wallet application. The frequency of using ewallet application as much as 2 times a week with nominal transactions dominated between Rp 200,000 - Rp 300,000. The type of transaction used by respondents is the purchase of food and beverage messages between online. Based on the results of this study, perceived ease of use has a significant positive effect on the perceived usefulness of e-wallet applications. Perceived usefulness has a significant positive effect on the intention to use ewallet application. Perceived ease of use has a significant positive effect on the intention to use e-wallet application. The results of this study also prove that there is a significant positive influence of advertising and product innovation on the intention to use e-wallet. While the cashback promo in this study has no significant effect on the intention to use e-wallet application.

Strategies to maximize new users and retain existing users on e-wallet applications are based on descriptive analysis results, demographics, user behavior and SEM analysis results. In general, the strategies formulated in the mix are: 1) create user friendly features to attract new users and retain existing users; 2) maintain the quality of transaction services in terms of speed, ease and practicality; 3) improve service access when toping up and transferring balances to other users; 4) service providers need to educate and socialize about e-wallets by utilizing cashback promos; 4) improve security systems to safeguard users' personal data; 5) the need for a legal umbrella for app users; and 6) increase the number of merchant ewallet applications.

\section{Acknowledgement: None}

Conflict of Interest: None

\section{Source of Funding: None}

\section{REFERENCES}

1. Adhiputra MW. 2015. Application technology acceptance model against the 
use of internet banking services. Kalbisocio. 2(1),52-63

2. Agus K, Diana S, Andy, Tjong S. 2019. The effect of discounts on e-wallet applications on the growth of impulsive purchasing interest of millennial consumers in the Tangerang area. Journal of Management Science. 5(2): 137:160

3. Agustina H. 2017. The use of information technology, ease and features of services to the customer's interest in using internet banking. Journal of Performance Management. 3(1): 24-29

4. Ghozali I. 2014. Structural Equation Modeling, An Alternative Method with Partial Least Square (PLS) is equipped with Smartpls 3.0 Xlstat 2014 and WarpPLS 4.0 software. 4th Ed. Semarang (ID): Diponegoro University Semarang.

5. Ghozali. I. 2012. Multtivariate Analysis Application with IBM SPSS Program. Yogyakarta (ID): Diponogoro University

6. Hair J.R., Anderson R.L. Tatham W.C, Black. 2006. Multivariate Data Analysis With Reading, Sixth Editions. New York (US): Mc Milan Pub. The Company.

7. Im JY, Hancer M. 2014. Shaping traveler's attitude toward travel mobile application. Journal of Hospitality and Tourism Technology. 5(2): 177-193
8. Iprice. 2019. Indonesia E-commerce Map. [internet] [ accessed 2020 Aug 25]. Available on https://iprice.co.id

9. Ipsos Indonesia. 2020. Reasons for using digital wallets. [internet] [accessed 2020 November 20]. Available on https://databoks.katadata.co.id

10. Ipsos. 2020. Evolution of the Digital Wallet Industry: A Winning Strategy Without Burning Money. [internet] [accessed 2020 Dec 1]. Available on https://www.ipsos.com/sites/default/files/ct/ news/documents/2020- 12/ipsos__press_release_-_indonesian.pdf

11. Nazir M. 1998. Research Method. Jakarta (ID): Ghalia Indonesia.

12. Sumarwan U. 2017. Business and Consumer Research Methods. Bogor (ID): IPB Press.

13. Venkatesh V, Bala H. 2008. Techology acceptance model 3 and a research agenda on interventions. Journal Compilation 2008, Decision Sciences Institute.

How to cite this article: Salzabella S, Sumarwan U, Yuliati LN. Analysis of factors influencing consumers in using the e-wallet application. International Journal of Research and Review. 2021; 8(6): 45-58. DOI: https://doi.org/10. 52403/ijrr.20210608 